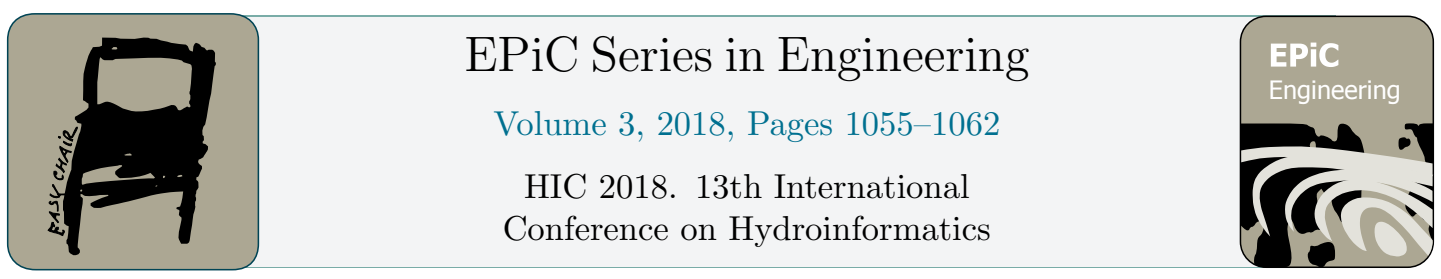

\title{
A serious game to explore different flooding scenarios and their respective effects on infrastructures
}

\author{
M. Khoury ${ }^{1}$, A. S. Chen', M. J. Gibson' ${ }^{1}$, L.S. Vamvakeridou-Lyroudia ${ }^{1}$, D. \\ Stewart $^{2}$, M. Wood ${ }^{2}$, D. A. Savic ${ }^{1}$, S. Djordjevic ${ }^{1}$ \\ ${ }^{1}$ Centre for Water Systems, University of Exeter, Exeter, EX4 4QF, UK \\ ${ }^{2}$ Torbay Council, Town Hall, Torquay, TQ1 3DR, UK
}

Corresponding author: m.khoury@exeter.ac.uk

\begin{abstract}
Using the Unity3d game engine, a Serious Game has been developed to explore different flooding scenarios under climate change in the town of Torbay in Devon, United Kingdom, and discover the resulting consequences on different critical infrastructures, aiming at enhancing their resilience. The system also sports a rather unique 3D navigable information board comprised of a virtual table populated with documents and interactive post-it notes introducing a compelling narrative.
\end{abstract}

Keywords: flood visualization - serious game - critical infrastructures

\section{Introduction and background}

There exist many tools for visualising flood events. Many of these tools focus on visualising the sea level rise for a specific location [1] such as for example the Sea Level Rise and Coastal Flooding Impacts Viewer [2], New Jersey Flood Mapper [3], Flood map Brussels [4], Explore Sahul Time [5], Interactive Sea Level Rise Web Map [6], Surging Seas [7], What Could Disappear [8]. Although 3D visualisations have been successfully employed to evaluate infrastructure damages from fire [9] or earthquakes [10], they have not yet realised their potential in the domain of flood risk management [11-12]. Presently, 3D models of flood risk management [13-15] tend to focus [1] on the static 3D visualisation of flood hazard as in the example in Figure 1. Flood visualisations tools that show change throughout time tend to focus on flood damage assessment to infrastructures rather than the change in the $3 \mathrm{D}$ shape of the flood. In TUFLOW [16], the intensity, horizontal velocity and rising velocity of flood 
events are used to visualise damage in 2D. In DisasterMap [17], residential structural damages to buildings are estimated in percentages.

In this paper we present a dynamic visualisation system, showing the progression of flood depth and extent. It can also identify the risk to critical infrastructures (CIs). This feature will help the end-users to better understand the evolution of potential flood impact, for future scenarios under climate change. The visualisation system presented in this paper, is entirely written in C Sharp and uses the "Unity ${ }^{\circledR}$ " (or Unity3d) software [18], the most used commercial game engine in the video game industry. The engine enables users to view and interact with accurately via $3 \mathrm{D}$ environment and we have added the function allowing the deformation of terrain and flood surfaces in realtime, provided the modelling data are supplied in standard image formats.

Unity3d has by default no optimised way to visualise the change in the 3D shape of the flood over a terrain. As such, the Unity3d default terrain object has several resulting shortcomings:

(i) The degree of precision used to render the terrain heightmap is insufficient as it cannot render a mesh with subtle differences in height. Presently, the terrain engine only takes 16 bits raw images as input, which limit the precision to $2^{\wedge} 16$ or 65536 unique values. Assuming the terrain height range was set to $2000 \mathrm{~m}$, the setting would provide an approximate resolution of $3.05 \mathrm{~cm}(2000 \mathrm{~m} / 65536)$ which is too coarse as a $3 \mathrm{~cm}$ difference in water level is not negligible.

(ii) The default terrain is unable to display consistently overlapping meshes at different altitude levels as shown in picture 1. As soon as the user "zooms out", high detail meshes are substituted with simplified one automatically via a forced optimisation process that is great and suitable for ordinary games, but not for visualising flood.
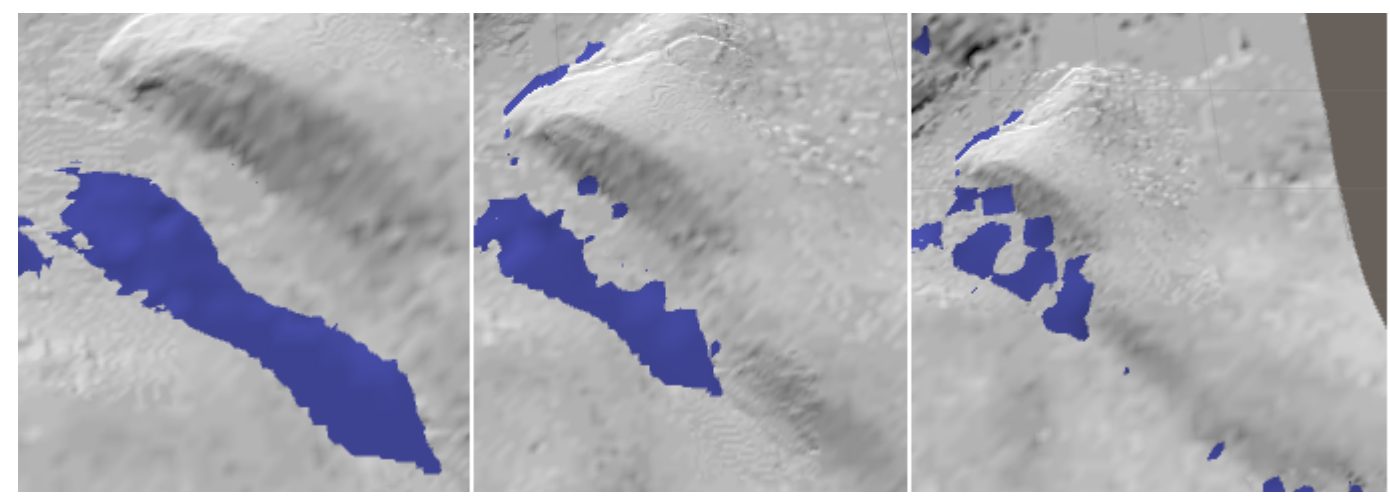

Figure 1 By default, the further away the observer is from the terrain, the more the Unity3d terrain object does deform meshes by substituting highly detailed meshes with simplified ones. 
(iii) Finally, the default process by which detailed terrain and flood meshes are animated is too slow to allow real time changes, especially on machines with less than stellar graphic capabilities. In the next section, we describe how our system addresses these shortcoming, and then show added functionalities regarding the visualisation of a narrative framework as well as the impact of flood on CIs failure.

\section{Methodology}

We first detail how we improved the Unity3d game engine to allow the visualisation of 3D animated floods. We then show the flood modelling part is connected to the visualisation of infrastructure failure. Finally, we present a visual narrative framework that encapsulates all the elements described above in a way that is suitable for Serious Gaming.

\subsection{The visualisation of 3D animated floods}

The 3D rendering engine has been modified to allow the terrain/flood height to be rendered with a higher degree of precision. The height data are provided by standard images in .png format where each pixel's red, green, blue, and alpha values encode in 32 bits the height of the terrain. From a practical point of view, these floating-point data of height are rescaled into large integer numbers, between 0 and $2^{32}$ (i.e. which allows the system to display the tiniest difference in height to the sub $\mathrm{mm}$ level). Furthermore, by using .png rather than Unity $3 \mathrm{~d}$ default raw file format, more compact images are produced that can easily be sent through the internet. Although, so far, the data are stored locally with the game, whole sequences of images could potentially then be sent from a "game" server hosting many test cases to provide multiple animations steps through a flood sequence.

Terrain and flood surfaces can now be deformed in real-time using advanced Shaders [19] effects exploiting graphic cards computational capabilities. Shaders - programs implemented in the OpenGL Shading Language to display vertices and visual fragment using the accelerated computational power of the graphic card - are implemented to output in real time a 3D geometric linear interpolation of the flood "height-map" between the starting and the end state by looking at the "counter" input. Flood animation is implemented by providing as input two images and a "counter" float number between 0 and 1 , expressing how far the animation is from the end stage. The Shaders are not only engineered to deform 3D meshes efficiently, but also change the flood mesh colour gradient from clear blue to dark blue with increasing flood depth. This works seamlessly even on fairly modest machines or small laptops, animating meshes with more than 1,440,000 triangles in real time with ease, as long as they have a directx 11 compatible graphic card. 


\subsection{A system to visualise consequences of flooding on critical infrastructures}

All objects such as per examples 3D buildings can be easily changed in an interactive manner. Flood depths encoded in images are produced using the WCA2D flood model [20], a part of the CADDIES-2D [21-22] modelling framework. CADDIES-2D is an open-source framework designed to facilitate the design and deployment of Cellular Automata (CA), specifically for 2D urban flood modelling. It is ideal for doing fast flood evaluations in the context of serious gaming. In the present work, the flood models were pre-run to produce output images used to make the $3 \mathrm{~d}$ animated mesh of the flood.

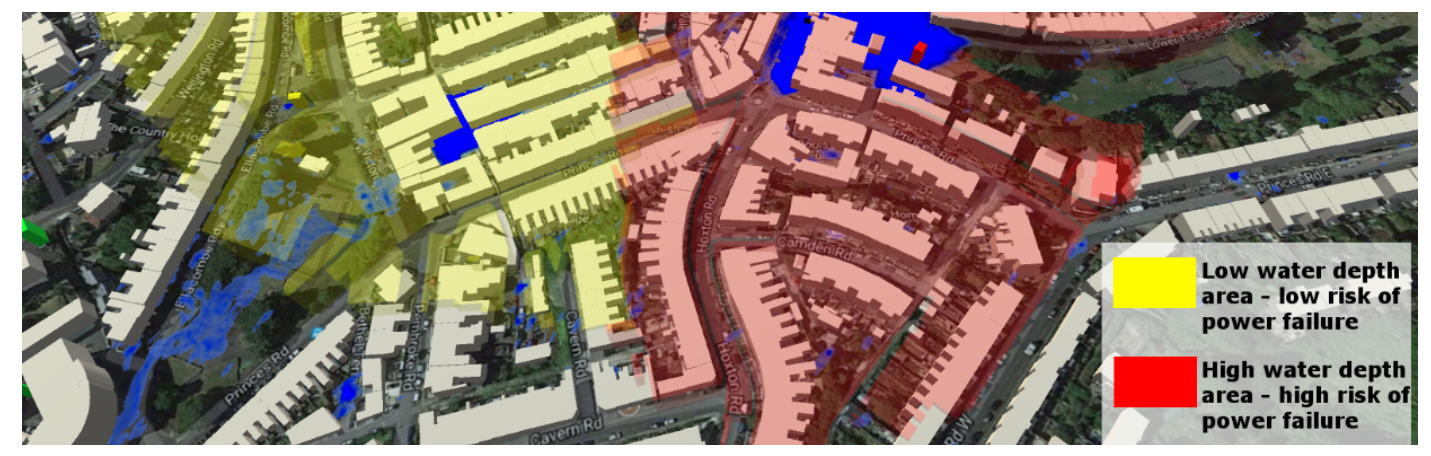

Figure 3 Substation failures and dependent power outage areas.

We adopted the EU-CIRCLE framework [23], which was applied to analysed the cascading effect of CI failures. Damage curves in function of flood depth are applied to CIs such as sub stations are shown as coloured buildings. Once the flood depth reaches a level that could cause damage to buildings or affect the functioning of CI, different colours will be highlighted to demonstrate the impact of flooding, as shown in Figure 3. The green/yellow/red buildings indicate the locations of substations. The green ones represent the substations having less than $0.05 \mathrm{~m}$ water depth in nearby area such that they are not affected by flooding. The yellow ones have flood depth between $0.05-0.3 \mathrm{~m}$ that there is a small chance of power supply service disruption, and the areas receiving the service from those stations are shaded in yellow as well. The red buildings are the ones with $0.3-1.0 \mathrm{~m}$ flood depth that the substations are likely to be damaged and fail to provide service to their servicing areas shades in red. Details of the methodology are described in the related publications [23-24].

\subsection{A serious game with a narrative framework}

A 3D virtual table that comprises different informative documents and interactive post-it notes introducing the case has been constructed as shown in Figures 4 and 5 to provide additional information to the users. 


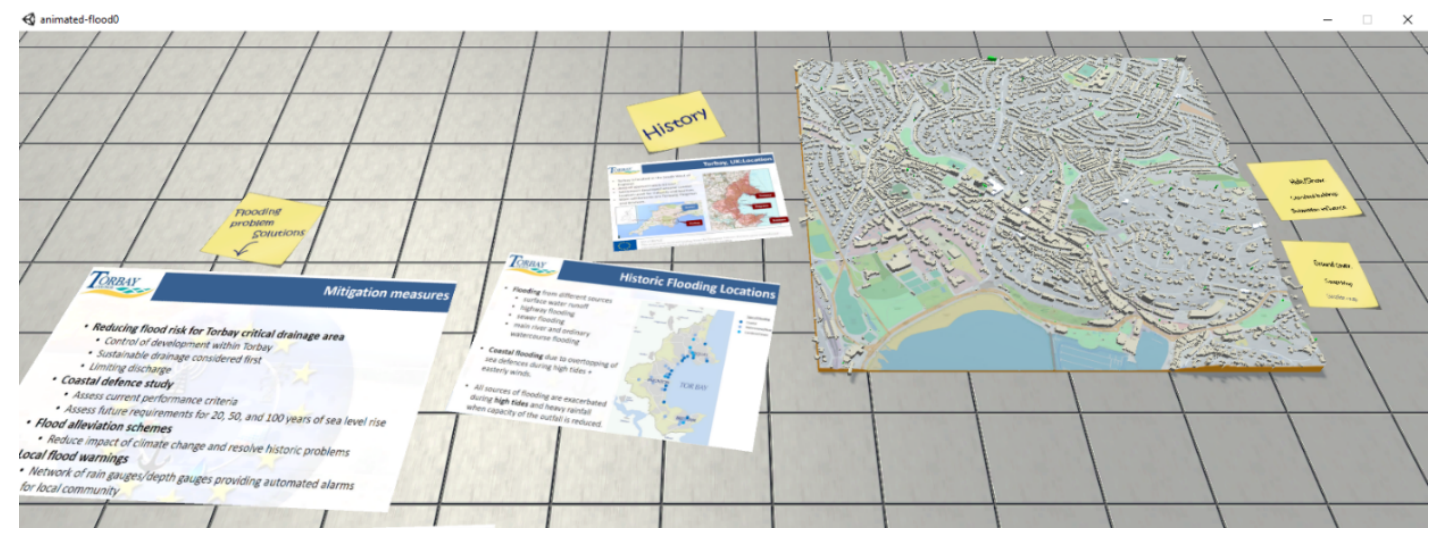

Figure 4 Overview of the 3D virtual table with narrative and interactive elements

This innovative and original setting for flood visualisation is quite powerful and expandable as follows:

(i) It allows the display of vast amounts of information on a virtual table of practically infinite size (Figure 5).

(ii) It can also structure this information visually so that the user can see how components are related to each other in the case study, move, rotate and zoom around at the user's leisure, and finally display geographically distant elements as interconnected infrastructure nodes.

(iii) Furthermore, this setting is easily translatable as a Virtual Reality based Serious Game without major code modification.

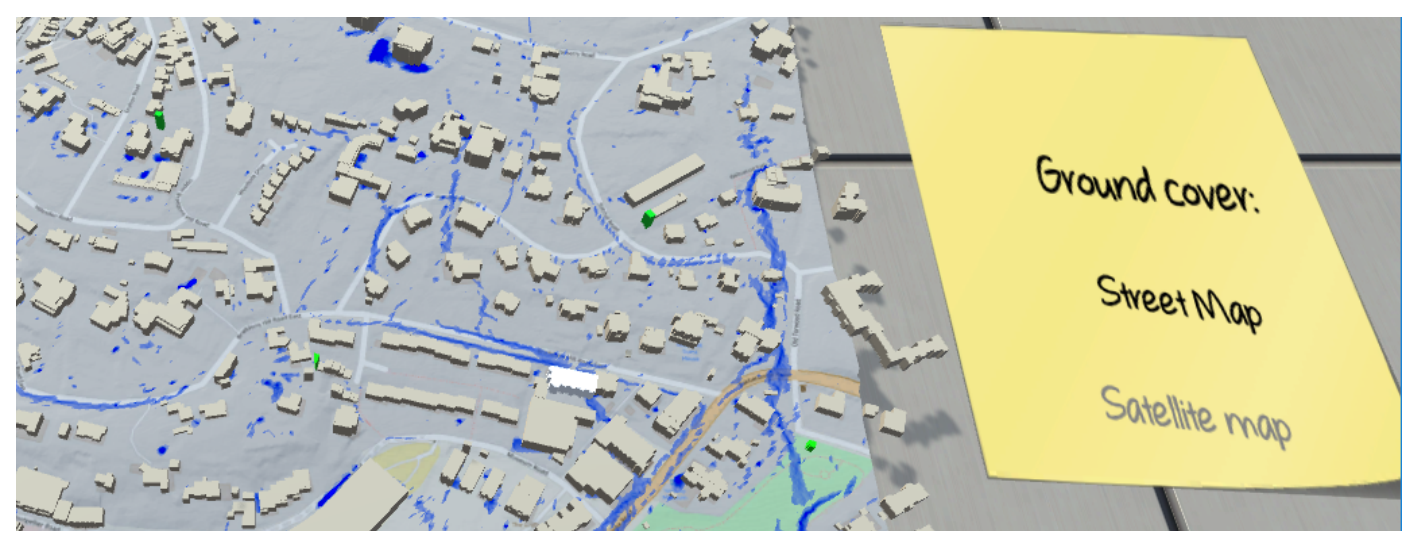

Figure 5 Detail of $3 \mathrm{~d}$ virtual table. The town mesh with the flood print over a portion of Torbay is visible. Interactive "post-it" on the side allows actions that impact the narrative framework. 


\section{The Torquay Test Case}

We simulated a flood event over a portion of the town of Torquay in the UK, with a uniform rain input of $40 \mathrm{~mm}$ in one hour that was equivalent to a 1 in 100 -year event. The event was simulated for three hours to allow the runoff to propagate further downstream after the rain stopped. As shown in Figure 6, five areas with power substations were impacted by the flood, with two of them in dark brown that are highly likely to suffer the consequence of CI failures.

The town hall is located in one of the areas deprived of electricity, a fact that was understood by the stakeholders through visualisation, during a demonstration workshop held at the University of Exeter, organised by Torbay Council (October 2017). This fact sparked a debate among the stakeholders regarding the need for identifying primary and secondary affected assets in order to also model the indirect impact of cascading failure over the infrastructures and services, which led to virtually playing (examining) further scenarios and mitigation strategies for flood impacts. The project is still ongoing, with the final results to be presented in 4-6 months' time.

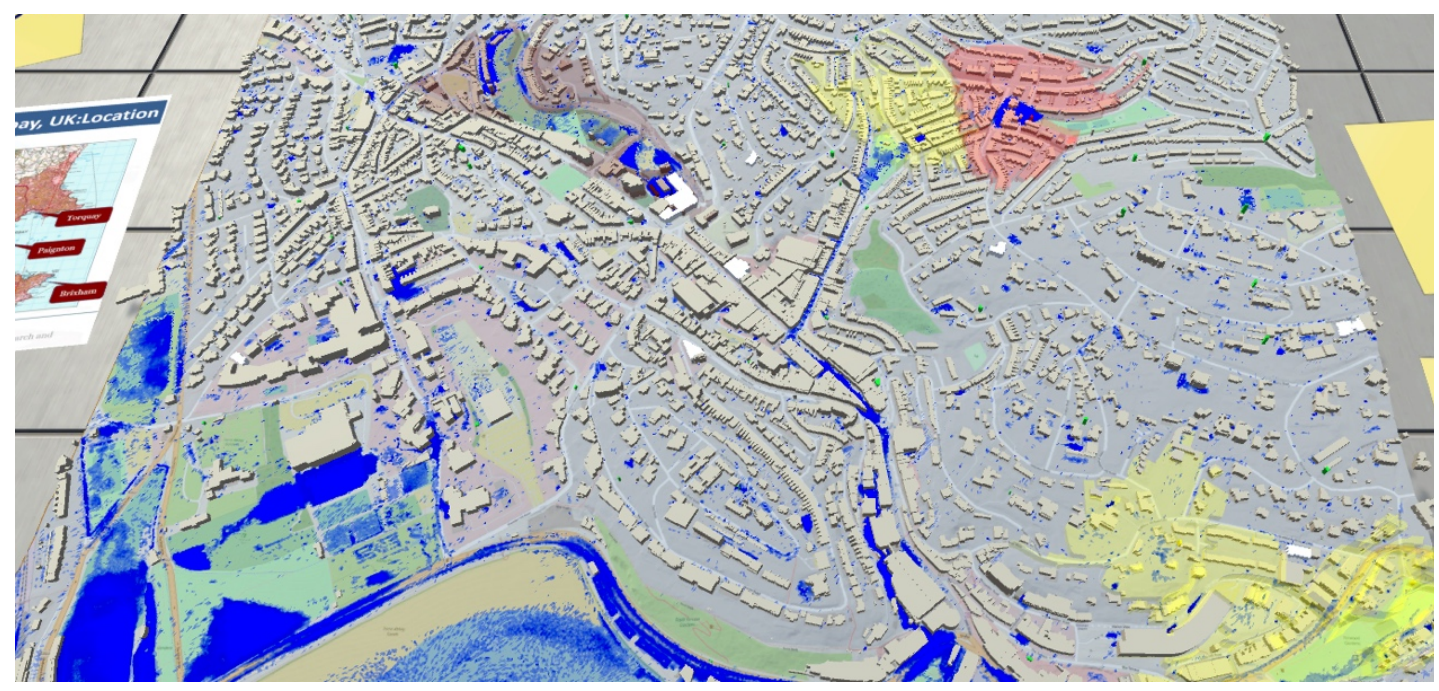

Figure 6 View of the areas where power sub stations were impacted by the flood. The degree of the failure varies from light (yellow), to medium (red) and severe (brown)

\section{Conclusions and future work}

This work presented in this paper is an innovative step towards visualising flood impacts and include them in Serious Games. It also introduces a more effective software package for exploring the consequences of different flooding scenarios on critical infrastructures. The resulting Serious Game is promising and expandable for examining possible flood impacts under different mitigation and/or adaptation measures. Moreover it can be expanded to other types of critical infrastructure 
protection in the future. Currently, within this project, work is ongoing about a more detailed model to quantify the impact of service disruptions, so as to evaluate the effectiveness of adaptation strategies to enhance resilience, while also, a more complex serious game narrative exploring branching scenarios involving multiple stakeholders is being investigated.

\section{Acknowledgements}

The work presented in this paper was partially funded by the ongoing EC H2020 EUCIRCLE (GA 653824) and the FP7 PEARL (Preparing for Extreme And Rare events in coastal regions, GA 603663) projects. The development of CADDIES model was funded by the UK Engineering and Physical Sciences Research Council, grant EP/H015736/1 (Simplified Dual-Drainage Modelling for Flood Risk Assessment in Urban Areas). The authors would also like to acknowledge the funding provided by the UK Engineering and Physical Sciences Research Council, grant EP/M018865/1 (The Nexus Game). They would also thank the Environment Agency, Ordnance Survey (GB), and Torbay Council for the provision of data.

\section{References}

[1] Van Ackere S, Glas H, Beullens J, Deruyter G, De Wulf A, De Maeyer P. Development Of A 3d Dynamic Flood Web Gis Visualisation Tool. Flood Risk Management and Response (2016): 106.

[2] NOAA Coastal Services Center. Sea Level Rise and Coastal Flooding Impacts 2015. URL https://coast.noaa.gov/slr/ (accessed March 29, 2016).

[3] JCNERR, CRSSA, NOAA CSC SN, Rutgers University. Sea Level Rise and Coastal Flooding Impacts 2015 URL http://54.243.129.238/SLR.html\# (accessed March 29, 2016).

[4] Leefmilieu Brussel. Overstroming URL http://geoportal.ibgebim.be/webgis/Overstroming_kaart.phtml (accessed April 11, 2016).

[5] Monash University. Explore SahulTime URL http://sahultime.monash.edu.au/explore.html (accessed March 29, 2016).

[6] SBEP \& MOTE Marine Laboratory. Interactive Sea Level Rise Web Map URL http://geology.com/sea-level-rise/florida.shtml (accessed March 29, 2016).

[7] Climate Central. Surging Seas: Risk Zone Map URL http://ss2.climatecentral.org/\#12/40.7298/-74.0070? show $=$ satellite\&projections $=0$ RCP85-SLR\&level=5\&unit=feet\&pois=hide (accessed March 29, 2016).

[8] NY Times. What Could Disappear URL:

http://www.nytimes.com/interactive/2012/11/24/opinion/sunday/what-coulddisappear.html?_r=0 (accessed March 29, 2016).

[9] Ruppel U, Schatz K. Designing a BIM-based serious game for fire safety evacuation simulations. Adv Eng Informatics 2011;25:600-11. doi:10.1016/j.aei.2011.08.001.

[10] Christodoulou SE, Vamvatsikos D, Georgiou C. A BIM-based framework for forecasting and visualizing seismic damage, cost and time to repair. eWork Ebus Archit Eng Constr Proc Eur Conf Prod Process Model 2010 2010:33-8. 
[11] Isikdag U. A SWOT analysis on the implementation of Building Information Models within the Geospatial Environment. Urban Reg Data Manag UDMS Annu 2009:15-30.

[12] Leskens JG, Kehl C, Tutenel T, Kol T, Haan G de, Stelling G, et al. An interactive simulation and visualization tool for flood analysis usable for practitioners. Mitig Adapt Strateg Glob Chang 2015. doi:10.1007/s11027-015-9651-2.

[13] Kemec S, Zlatanova S, Duzgun HS. A Framework for Defining a 3D Model in Support of Risk Management. Geogr Inf Cartogr Risk Cris Manag 2010:69-82. doi:10.1007/9783-642-03442-8.

[14] Mioc D, Anton F, Nickerson B, Santos M, Adda P, Tienaah T, Ahmad A, Mezouagh M, MacGillivray M. Flood progression modelling and impact analysis. Gi4DM (Geoinformation Disaster Manag. Conf., 2011.

[15] Swiss Federal Geoportal URL https://map.geo.admin.ch

[16] TUFLOW URL http://www.tuflow.com/ (accessed April 4, 2016).

[17] Disastermap. Residential structural damage in New Orleans URL http://disastermap.net/wordpress/wp-content/uploads/2015/08/Residential-DamagePoints.jpeg (accessed April 12, 2016).

[18] "Unity®" (or Unity3d) software - URL https://unity3d.com/ (accessed March 11, 2018)

[19] Lammers K. Unity Shaders and Effects Cookbook. Packt Publishing, 2013.

[20] Guidolin M, Chen AS, Ghimire B, Keedwell EC, Djordjević S, Savić DA (2016), A weighted cellular automata 2D inundation model for rapid flood analysis, Environmental Modelling and Software, 84, pp. 378-394, 2016.

[21] CADDIES framework University of Exeter, April 2016. [Online]. Available: emps.exeter.ac.uk/engineering/research/cws/resources/caddies-framework/.

[22] Gibson M, Savic D, Djordjevic S, Chen A, Fraser S, Watson T, Accuracy and computational efficiency of 2D urban surface flood modelling based on cellular automata, Procedia Engineering, Incheon, South Korea.

[23] Sfetsos A, Vamvakeridou-Lyroudia LS, Chen AS, Khoury, M, Savic DA, Djordjevic S, Eftychidis G, Leventakis G, Gkotsis I, Karavokyros G, Koutiva I, Makropoulos C, (2017). 'Enhancing the resilience of interconnected critical infrastructures to climate hazards', Proc. 15th International Conference on Environmental Science and Technology, CEST2017, Rhodes, Greece, 31 August to 2 September 2017

https://cest.gnest.org/sites/default/files/presentation_file list/cest201700851_oral_paper. pdf

[24] Chen AS, Khoury M, Vamvakeridou-Lyroudia L, Stewart D, Wood M, Savic D, Djordjevic S. 3D visualisation tool for improving the resilience to urban and coastal flooding in Torbay, UK, Procedia Engineering, Volume 212, Pages 809-815, 2018.

[25] Gibson MJ, Chen AS, Khoury M, Vamvakeridou-Lyroudia L, Stewart D, Wood M, Savic D, Djordjevic S. Analysing the cascade effects on critical infrastructure in Torbay coastal/pluvial flooding with climate change, Hydroinformatics 2018, Palermo, Italy . 